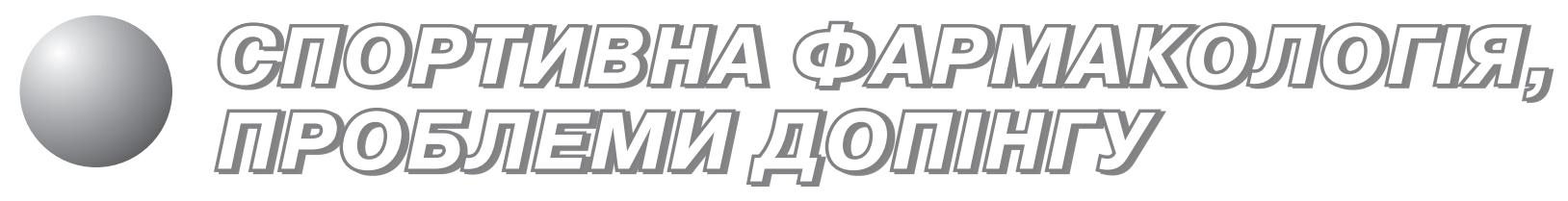

\section{Гемостимулирующие свойства поливитаминных препаратов и витаминно-минеральных комплексов, используемых в спорте}

\author{
Б. М. Мыцкан, Т. С. Мыцкан
}

Прикарпатский национальный университет имени Василия Стефаника, ИваноФранковск, Украина

\begin{abstract}
Резюме. Проведено порівняльний аналіз гемостимулюючих властивостей сучасних полівітамінних препаратів і вітамінно-мінеральних комплексів для спортсменів. Проаналізовано препарати десяти країн-виробників. Для визначення ступеня гемостимулюючого впливу досліджуваних фармакологічних препаратів нами запропоновано методику визначення гемо стимулюючого індексу препарату, який дозволяє швидко визначити ефективність його впливу на гемопоез спортсменів. За показниками індексу гемостимулюючої потужності до категорії лідерів необхідно віднести такі препарати: “Активал», «Теравит», «Центрум», а також препарати серії «Витрум», тому що їх гемостимулюючий вплив найбільш представницький (за 15 гемостимулюючими речовинами).
\end{abstract}

Ключові слова: гемостимуляція, вітаміни, вітаміно-мінеральні комплекси, спортсмени.

\begin{abstract}
Summary. Aim of this work was to conduct a comparative analysis of the stimulating properties of hemo modern multivitamin preparations and vitamin and mineral complexes for athletes. Ten countries of analyzed drugs manufacturers. To determine the degree of hemo stimulating effect of pharmacological agents we studied the technique of determining the index of hemo stimulating drug that can quickly determine its impact on the effectiveness of hematopoiesis athletes. In terms of index hemo enabling power to the category leaders should include the following drugs: "Actival», "Teravyt", "Centrum» and medications series «Vitrum» because of their stimulating effect of hemo most representative (15 hemostimulating substances).
\end{abstract}

Key words: hemo stimulation, vitamins, vitamin mineral complexes, athletes.

Постановка проблемы. Стимулирование процессов кровообразования является одним из путей повышения функциональных свойств организма и соответственно - фризической работоспособности спортсмена. Известно, что все витамины, витаминоподобные вещества и подавляющее большинство минеральных соединений имеют регуляторное влияние на ход биохимических и фризиологических процессов в организме и достаточно часто используются в практике спорта с целью активизации метаболических процессов в тканях (прежде всего в главных скелетных мышцах) для отсрочки времени наступления утомления, предупреждения перетренированности, а также для усиления процессов восстановления [1].
Предварительно проведен анализ химического состава поливитаминных препаратов и витаминно-минеральных комплексов, которые часто используются в практике спорта для определения наличия и содержания в их составе витаминов, витаминоподобных и минеральных веществ с гемостимулирующими свойствами. Анализ показал, что во многих случаях они существенно различаются между собой.

Цель исследования - установить гемостимулирующий спектр и провести сравнительный анализ гемостимулирующих свойств современных поливитаминных препаратов и витаминно-минеральных комплексов, используемых в практике спорта, с целью улучшения процес- 
сов кровообразования при фризических нагрузках.

Методы исследования.Гемостимулирующие свойства (ГС) того или иного препарата оценивали по индексу гемостимулирующей мощности препарата (индекс ГСП). Исходными данными для определения этого индекса являются: количество гемостимулирующего вещества в составе препарата; общая масса этих веществ.

Результаты исследования и их обсуждение. Проанализированы 22 современных поливитаминных препарата и витаминно-минеральных комплексов по их витаминно-минеральному спектру, а также по наличию в их составе веществ гемостимуляторов. К списку исследуемых поливитаминных препаратов (ПВП) и витаминно-минеральных комплексов (ВМК) вошли препараты отечественного и иностранного производства, рекомендуемые для спортсменов к употреблению и фигурирующие на современном фрармакологическом рынке Украины: Аскорутин, Гексавит, Декамевит, Квадевит, Комплевит, Ундевит, Активал, Дуовит, Макровит, Пиковит, Полиговит, Прегнавит, Супрадин, Витрум, Витрум юниор, Витрум энерджи, Теравит, Три-ви плюс, Центрум, Витакап, Иммуновит С, Лютеин комплекс.

Как видно из приведенного перечня препаратов, географический спектр исследуемых ПВП и ВМК достаточно представителен и охватывает 10 стран-производителей трех континентов: Европы (Великобритания, Германия, Словения, Венгрия, Украина, Югославия, Польша, Россия); Северной Америки (США) и Азии (Таиланд).

У всех 22 проанализированных ПВП и ВМК содержание отдельно взятых витаминов-ГС колеблется от одного (в препаратах: Лютеин комплекс, Три-ви плюс) до восьми (в препаратах: Активал, Витрум, Витрум энерджи, Витрум юниор, Квадевит, Супрадин, Теравит, Ундевит и Центрум). Следует отметить, что максимального количественного присутствия витаминов и ВПР с гемостимулирующими свойствами (10) в составе одного из исследованных препаратов не зарегистрировано. Обращает на себя внимание тот факт, что в составе всех препаратов отсутствует такая гемостимулирующая составляющая, как оротовая кислота (витамин $\mathrm{B}_{13}$ ). Что касается отдельно взятых витаминов-ГС, наиболее представлен в исследованных препаратах витамин С (аскорбиновая кислота), который входит в состав 22 препаратов, а наименьшее - витамин $\mathrm{H}$ (шесть препаратов) и $\mathrm{P}$ (семь препаратов).

По содержанию отдельных минералов-ГС в проанализированных ПВП и ВМК то ОН ко- леблется от нуля (три препарата: Аскорутин, Гексавит и Иммуновит С) до семи (максимально возможное количество - семь препаратов: Активал, Витрум, Витрум энерджи, Витрум юниор, Дуовит, Теравит и Центр). Относительно отдельно взятых минералов с гемостимулирующими свойствами, наибольшее представительство в исследованных препаратах принадлежит кальцию (Са), который входит в состав 19 препаратов из 22, а наименьшее - хрому (входит в состав восьми препаратов). В целом полученные данные дают основания констатировать, что вещества-ГС (витамины-ГС и минералы-ГС) присутствуют во всех без исключения (22) исследованных препаратах, а их количественное представительство колеблется в пределах от 2 до 15 (с максимально возможным общим количеством 17).

Не вызывает никаких сомнений тот фракт, что для максимально эффрективной стимуляции процессов гемопоэза у спортсменов следует учитывать, по нашему мнению, не только общее количество веществ-ГС, но и степень сбалансированности витаминов-ГС и минералов-ГС в составе того или иного препарата. Только при таком подходе можно достичь более-менее ощутимого гемостимулирующего эффректа. В этом аспекте проведенный нами сравнительный анализ всех исследуемых (22) ПВП и ВМК дает достаточно объективные основания разделить их на три группы.

В первую группу вошли препараты с относительно малым количеством (2-4), а также ощутимым дисбалансом витаминов-ГС и минералов-ГС. Вторую группу составили препараты со средним количеством веществ-ГС (9-11), но одновременно с существенным дисбалансом витаминов и минералов - ГС. К третьей группе мы отнесли ВМК со сравнительно высоким общим количеством (12-15) и хорошей сбалансированностью веществ-ГС между собой (табл. 1).

По показателям индекса гемостимулирующей мощности к категории лидеров необходимо отнести следующие препараты: Активал, Теравит, Центрум, а также препараты серии Витрум, поскольку их гемостимулирующий спектр является самым представительными (по 15 веществ-ГС).

Обнаруженные нами существенные различия в возможностях оценки гемостимулирующих свойств ПВП и ВМК по количественному представительству веществ-ГС, с одной стороны, и по массе веществ-ГС - с другой, создают вполне реальные трудности для тренеров и спортсменов в ситуациях выбора наиболее эфрфективных 
ТАБЛИЦА 1 - Распределение поливитаминных препаратов и витаминно-минеральных комплексов по количественному содержанию и сбалансированностью веществ-ГС*

\begin{tabular}{|c|c|c|c|c|c|}
\hline \multicolumn{2}{|c|}{1} & \multicolumn{2}{|c|}{ II } & \multicolumn{2}{|c|}{ III } \\
\hline Препарат & ГC, $\mathrm{Mr}$ & Препарат & ГС, мг & Препарат & ГС, $\mathrm{Mr}$ \\
\hline Иммуновит С & $2(2 /-)$ & Пиковит & $9(7 / 2)$ & Олиговит & $12(6 / 6)$ \\
\hline Аскорутин & $2(2 /-)$ & Комплевит & $9(7 / 2)$ & Витакап & $13(7 / 6)$ \\
\hline Гексавит & $4(4 /-)$ & Декамевит & $9(7 / 2)$ & Супрадин & $14(8 / 6)$ \\
\hline Лютеин комплекс & $4(1 / 3)$ & Макровит & $9(6 / 3)$ & Дуовит & $15(8 / 7)$ \\
\hline Три-ви плюс & $4(1 / 3)$ & Ундевит & $10(8 / 2)$ & Центрум & $15(8 / 7)$ \\
\hline & & Прегнавит & $10(7 / 3)$ & Теравит & $15(8 / 7)$ \\
\hline & & Квадевит & $11(8 / 3)$ & Активал & $15(8 / 7)$ \\
\hline & & & & Витрум энерджи & $15(8 / 7)$ \\
\hline & & & & Витрум & $15(8 / 7)$ \\
\hline & & & & Витрум юниор & $15(8 / 7)$ \\
\hline
\end{tabular}

* В скобках указано абсолютное количественное соотношение между гемостимулирующими витаминами и минералами в составе препарата.

препаратов для стимуляции процессов кровообразования.

Учитывая сказанное, мы провели поиск интегрального показателя для оценки гемостимулирующих свойств ПВП и МВК, который одновременно учитывал бы их количественные и качественные харатеристики - численность и общий вес веществ-ГС в составе конкретного взятого препарата. Таким показателем, на наш взгляд, может быть индекс гемостимулирующей мощности (индекс ГСП) препарата. Предложенная нами методика определения этого индекса доступна и удобна в пользовании.

Исходными данными для определения индекса ГСП препарата являются: 1) количество веществ-ГС (вместе витаминов и минералов-ГС) в его составе, общая масса этих веществ (мг). Данная инорормация приведена в инструкции по эксплуатации, прилагаемой фрирмой-производителем к каждому препарату.

Введя исходные данные относительно общего количества и массы веществ-ГС в специальную расчетную фрормулу, получаем числовое значение индекса ГСП для конкретного препарата:

$$
\Gamma \mathrm{CП}=\frac{\mathrm{К} Г \mathrm{C} \cdot \mathrm{MГC} \mathrm{(мг)}}{100},
$$

где КГС - общее число веществ-гемостимуляторов в составе препарата; 100 - коэффрициент уменьшения абсолютного числового значения индекса.

В качестве примера приводим описание методики расчета индекса ГСП препарата Супрадин. В его составе насчитывается 14 веществ ГС, общей массой 292,965 мг (для удобства можно пользоваться округленным до десятых числом 293,0 мг). Умножив 14 на 292,0, получаем число 4102. Поделив его на 100, имеем конечное значение индекса ГСП препарата Супрадин, что составляет 41,0. По показателям индекса гемостимулирующей мощности к категории лидеров необходимо отнести следующие препараты: Активал, Теравит, Центрум, а также препараты серии Витрум, поскольку их гемостимулирующий спектр является самым представительным (по 15 гемостимулирующих веществ).

\section{Выводы}

1. Гемостимулирующий эфффект в организме человека оказывают 17 витаминов и минералов: девять исходных витаминов (C, $\mathrm{P}, \mathrm{H}, \mathrm{Bc}, \mathrm{B}_{2}, \mathrm{~B}_{3}$, $\left.\mathrm{B}_{5}, \mathrm{~B}_{6}, \mathrm{~B}_{12}\right)$, одно витаминоподобное вещество (оротовая кислота), а также семь минералов, среди которых - шесть микроэлементов (железо, медь, кобальт, цинк, марганец, хром) и макроэлемент кальций.

2. Имеющиеся на современном фармацевтическом рынке Украины поливитаминные препараты и витаминно-минеральные комплексы по содержанию (количеству и массе) в своем составе веществ-гемостимуляторов довольно существенно различаются, поэтому далеко не все они могут быть успешно использованы как эффрективные стимуляторы гемопоэза у спортсменов.

3. Предложенный нами индекс гемостимулирующей мощности препарата позволяет быстро и точно определять гемостимулирующие возможности поливитаминных препаратов и витаминноминеральных комплексов, которые пополняют спортивный рынок фрармакологических средств для спортсменов. 


\section{Литература}

1. ВолкоВ Н. И. Биологически активные пищевые добавки в специализированном питании спортсменов / Н. И. Волков, В. И. Олейников. - М: СпортАкадемПресс, 2001. -80 с.

2. Мицкан Б. М. Гемостимулюючий спектр і механізми активуючого впливу вітамінів і мінеральних речовин на процеси кровотворення / Б. М. Мицкан, Ю. М. Завійський // Вісн. Прикарпат. ун-ту. Серія: Фізична культура. - 2008. Вип. 8. - С. 28-36.

\section{References}

1. Volkov N. I. Dietary supplements for specialized nutrition of athletes / N. I. Volkov, V. I. Olejnikov. - M: SportAkademPress 2001. - 80 p.

2. Mytskan B. M. Hemostimulating range and mechanisms activating effect of vitamins and minerals in the process of hematopoiesis. / B. M. Mytskan, Y. Zaviyskyy // Bulletin Prikarpatsky University. Series: Physical Education. -2008. Vol. 8. - P. 28-36. 